\title{
Effects of nerve compression on fast axonal transport in streptozotocin-induced diabetes mellitus
}

\author{
An experimental study in the sciatic nerve of rats
}

\author{
L. B. Dahlin ${ }^{1}$, K. F. Meiri ${ }^{4 *}$, W.G. McLean ${ }^{4}$, B. Rydevik ${ }^{1,2}$ and J.Sjöstrand ${ }^{3}$ \\ ${ }^{1}$ Laboratory of Experimental Biology, Department of Anatomy, ${ }^{2}$ Department of Orthopaedic Surgery I and ${ }^{3}$ Department of Ophthalmology, \\ University of Göteborg, Göteborg, Sweden; ${ }^{4}$ Department of Pharmacology and Therapeutics, University of Liverpool, Liverpool, UK
}

\begin{abstract}
Summary. The hypothesis that nerves in diabetes mellitus exhibit an increased susceptibility to compression was experimentally tested. Inhibition of fast axonal transport was induced by local compression in sciatic nerves of rats with streptozotocin-induced diabetes mellitus. Fast anterograde axonal transport was measured after application of ${ }^{3} \mathrm{H}-\mathrm{leu}-$ cine to the motor neurone cell bodies in the spinal cord. The sciatic nerve was subjected to local, graded compression in vivo by a small compression chamber. The amount of accumulation of proteins was quantified by calculation of a transport block ratio. Compression at $30 \mathrm{~mm} \mathrm{Hg}$ for $3 \mathrm{~h}$ induced a significantly greater $(p<0.05)$ accumulation of axonally transported proteins at the site of compression in nerves of diabetic animals (transport block ratio: $1.01 \pm 0.35 ; n=7$ ) than in nerves of controls $(0.67 \pm 0.16 ; n=7)$. Accumulation was sig-
\end{abstract}

nificantly higher in ligature experiments of both control $(1.34 \pm 0.44 ; n=8 ; p<0.01)$ and diabetic animals $(1.45 \pm 0.30$; $n=8 ; p<0.05$ ), indicating that the block of transport in compressed nerves was incomplete. Neither sham compressed diabetic $(0.50 \pm 0.09 ; n=6)$ nor control $(0.49 \pm 0.11 ; n=6)$ nerves showed any block of axonal transport. The possible causes of the increased inhibition of fast axonal transport in diabetic rats are discussed. The results indicate that diabetes may lead to an increased susceptibility of peripheral nerves to compression.

Key words: Compression, diabetes mellitus, streptozotocin, axonal transport, compression syndromes, mononeuropathy, neuropathy.
The clinical symptoms of neuropathy in diabetes mellitus are well known, and include primarily sensory complaints, occasionally accompanied by muscular weakness and autonomic symptoms. Sensory and muscular dysfunction in extremities may, however, also be caused by entrapment of peripheral nerves such as ulnar nerve compression at the elbow and median nerve compression at the wrist, i. e. the carpal tunnel syndrome. A high frequency of such mononeuropathies has been reported among diabetic patients, which suggests enhanced vulnerability of peripheral nerves to trauma [1]. It has also been suggested that peripheral nerves in experimental diabetes have a greater susceptibility to injury [2-4].

Axonopathy, which can be characterised by abnormalities in axonal transport, may be an important factor in the neuropathies which accompany diabetes [5-7]. Based upon previous experience on the effects of peripheral nerve compression [for review see 8] and the hypothesis that diseased neurones, such as those in diabetes mellitus, are more susceptible to compression

* Present address: Department of Anatomy and Neurobiology, Washington University, School of Medicine, St. Louis, Missouri, USA trauma than are healthy neurones [9], we decided to investigate the effects of experimental nerve compression on fast axonal transport in streptozotocin-induced diabetes mellitus

\section{Materials and methods}

\section{Animals and induction of diabetes}

Random-bred and weight-matched female Sprague-Dawley rats weighing $200-250 \mathrm{~g}$ were randomly divided into two groups. In one group ( $n=21)$ diabetes was induced with a single intravenous injection of $60 \mathrm{mg} / \mathrm{kg}$ body weight streptozotocin dissolved to a concentration of $30 \mathrm{mg} / \mathrm{ml}$ in $0.01 \mathrm{~mol} / \mathrm{l}$ citrate buffer, $\mathrm{pH} 4-4.5$, immediately prior to use. In the other group, control animals $(n=21)$ received an equivalent volume of citrate buffer. Whole blood glucose was measured with glucose sensitive reagent sticks (Dextrostix, Ames Division, Slough, England) on the third day after streptozotocin injection and at regular intervals thereafter. Only animals having whole blood glucose values above $13.9 \mathrm{mmol} / 1(250 \mathrm{mg} / 100 \mathrm{ml})$ were included in the diabetic group.

\section{Axonal transport}

Axonal transport measurements were made between 14 and 16 days after induction of diabetes. The rats were anaesthetized with an in- 


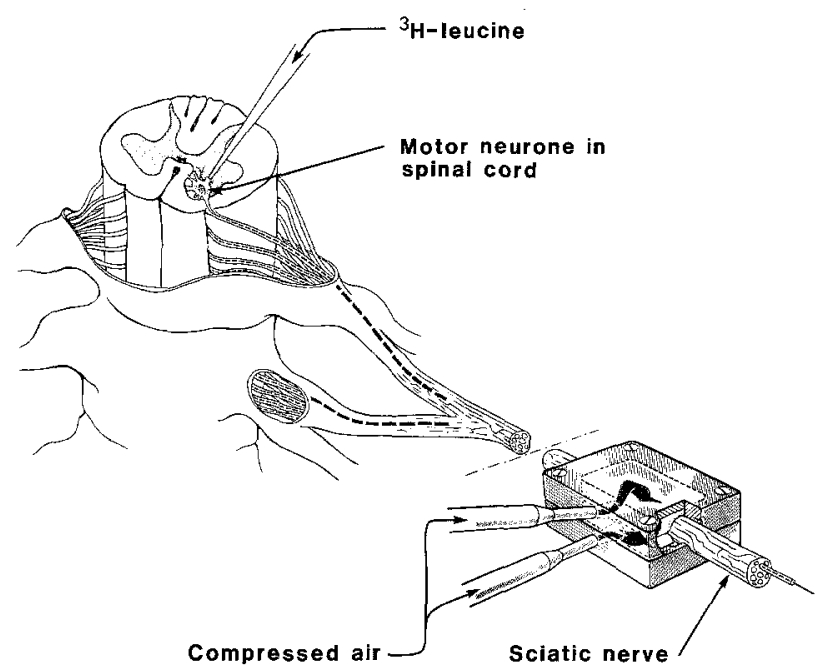

Fig. 1. Schematic drawing of experimental procedure. Axonally transported proteins were labelled by microinjection of ${ }^{3} \mathrm{H}$-leucine into the vicinity of the motor neurone cell bodies in the spinal cord. Four hours after labelling, a compression chamber or a ligature was applied around the sciatic nerve for a period of $3 \mathrm{~h}$

traperitoneal injection of a solution of pentobarbital $(60 \mathrm{mg} / \mathrm{ml})$ : $0.9 \%$ saline: diazepam $(5 \mathrm{mg} / \mathrm{ml})$ in $1: 1: 2$ volume proportions. Intraperitoneal injections of saline (total $10 \mathrm{ml}$ ) were given to the diabetic rats during anaesthesia to avoid excessive dehydration due to polyuria. The $\mathrm{L}_{4}$ and $\mathrm{L}_{5}$ spinal cord segments were exposed by a laminectomy of the $L_{1}$ and $L_{2}$ vertebrae. One hundred $\mu \mathrm{Ci}$ of $\mathrm{L}-\left[4,5{ }^{3} \mathrm{H}\right]$ leucine (specific activity $50 \mathrm{Ci} / \mathrm{mmol}$; Radiochemical Centre, Amersham, UK) were injected into the area of the motor neurone cell bodies through a glass micropipette with a tip diameter of $15 \mu \mathrm{m}$, according to the method of Lasek [10] as modified by Griffin et al. [11] and the exact spinal coordinates of Forman and Berenberg [12]. Four to eight injections (total $3 \mu \mathrm{l}$ ) were made each time (Fig. 1). The wound was then sutured, and the animals were placed in insulating cushions in order to keep the body temperature constant at $36-37^{\circ}$ (rectal temperature).

\section{Compression procedure}

Four hours later, with the animals again under anaesthesia, the left sciatic nerve was exposed in the thigh and carefully dissected free from surrounding tissue. A small compression chamber, consisting of two perspex halves onto which thin rubber membranes were glued, was then applied around the nerve trunk and secured with screws [13]. The chamber was connected to a compressed air system and inflated to a desired pressure level (Fig. 1), which was maintained for the remainder of the experiment. The length of the compressed nerve segment was $6 \mathrm{~mm}$. Both diabetic $(n=7)$ and control $(n=7)$ nerves were compressed at $30 \mathrm{~mm} \mathrm{Hg}$. Compression at this pressure for $2 \mathrm{~h}$ is the lowest pressure at which blockage of fast axonal transport in rabbit vagus nerve occurs [14]. In another set of both diabetic $(n=6)$ and control animals $(n=6)$, the compression chamber was applied around the sciatic nerve but not inflated (sham compression). Previous work has shown that the application of the chamber does not change nerve temperature [15]. In a third series of experiments, a ligature was applied around the nerve in both diabetic $(n=8)$ and control $(n=8)$ rats. The ligature was applied at the site where the proximal edge of the compressed area would be located.

\section{Determination of radioactivity}

Three hours after application of the chamber or ligature, the animals were killed by an overdose of pentobarbital and the sciatic nerve
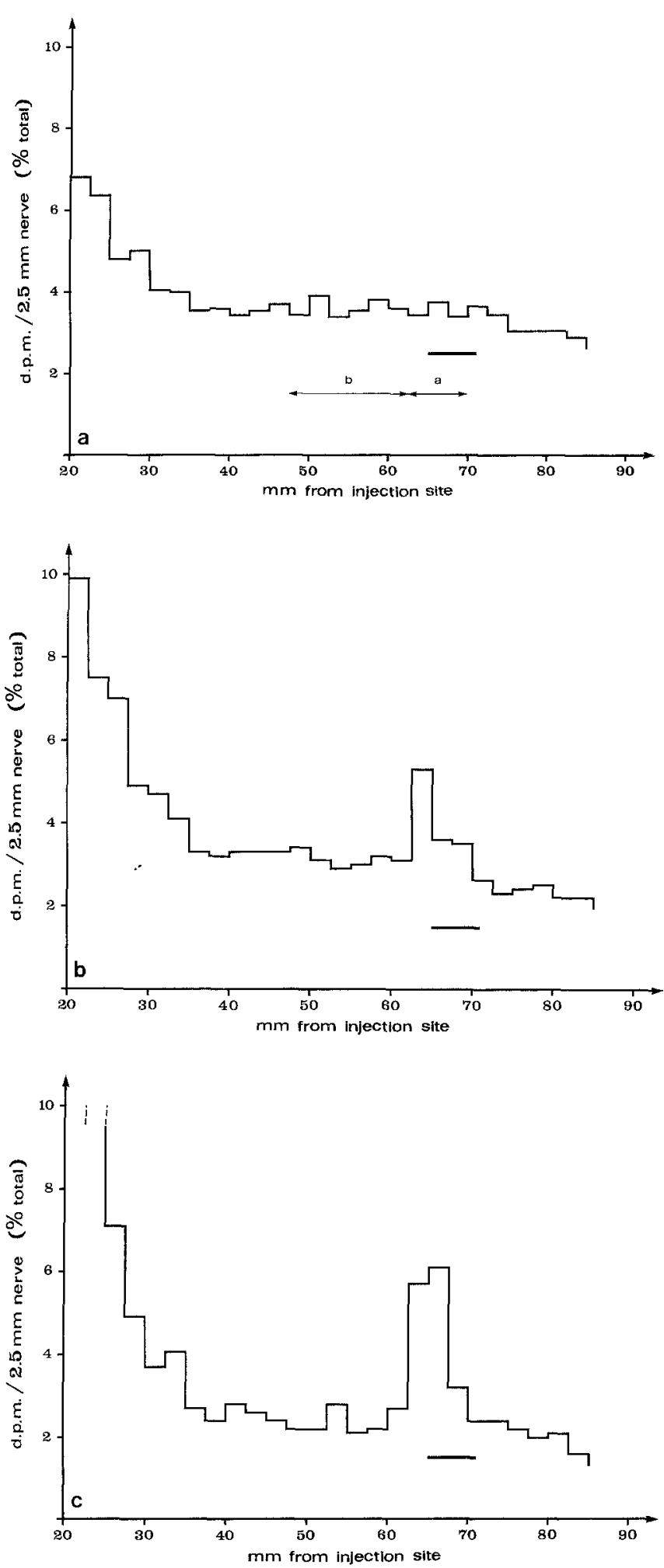

Fig. 2a-c. The profiles of radiolabelled proteins in a sham-compressed non-diabetic, b compressed non-diabetic and compressed diabetic sciatic nerves of rats $7 \mathrm{~h}$ after injection of isotope into the spinal cord. The nerves in $\mathbf{b}$ and $\mathbf{c}$ were compressed at $30 \mathrm{~mm} . \mathrm{Hg}$ for the final $3 \mathrm{~h}$. Results are mean of six or seven nerves. The black bars indicate the site of compression. The arrows indicate segments used for calculation of transport block ratio. Ratio $=\mathrm{a} / \mathrm{b}$ 


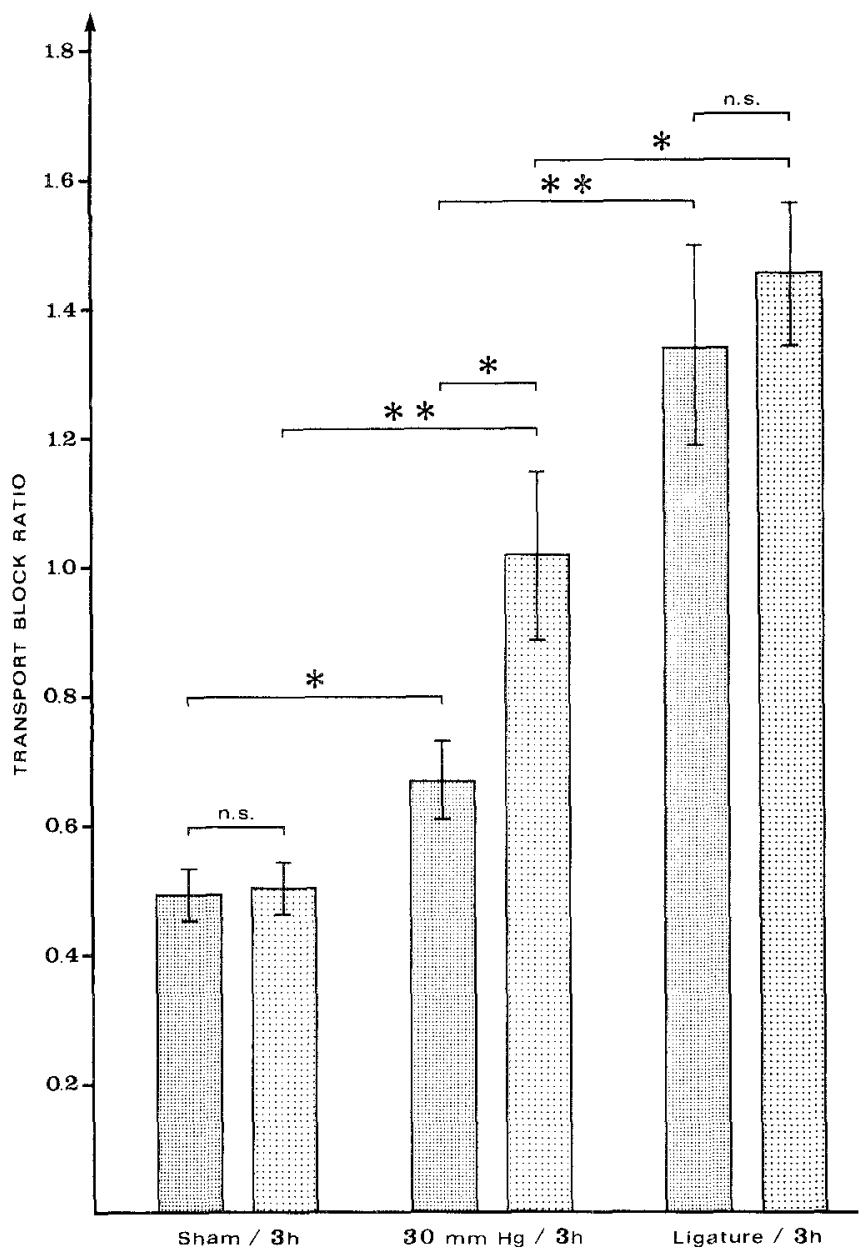

Fig. 3. Transport block ratio in control $\square$ and diabetic $\square$ nerves compressed at different pressures. Each bar is mean \pm SEM of six to eight experiments. Levels of statistical significance between relevant groups are indicated as $* p<0.05, * * p<0.01$ (Wilcoxon rank sum test; two-tailed)

quickly dissected out and frozen. A loose suture was placed around the nerve to indicate the position of the proximal edge of the compressed area. Each nerve was cut into $2.5 \mathrm{~mm}$ pieces and the pieces were soaked individually in $2 \mathrm{ml}$ cold $10 \%$ trichloroacetic acid (TCA) overnight. The pieces were washed once with a further $2 \mathrm{ml}$ TCA and dissolved in $0.4 \mathrm{ml}$ Soluene (Packard; Stockholm, Sweden) at room temperature. Two $\mathrm{ml}$ of toluene-based scintillation fluid were added to each dissolved nerve piece and the radioactivity of each sample was measured by liquid scintillation counting. The samples were corrected for quenching. The disintegrations per min (d.p.m.) in each $2.5 \mathrm{~mm}$ nerve segment were expressed as a percentage of the total radioactivity in the whole sciatic nerve $(85 \mathrm{~mm})$, excluding the first $20 \mathrm{~mm}$ from the injection site. In this way, any radioactivity present in the proximal segment due to diffusion of ${ }^{3} \mathrm{H}$-leucine from the injection sites and incorporation into non-neuronal proteins was excluded from the calculation $[6,16]$.

\section{Quantification of axonal transport inhibition}

The transport block ratio, which reflects the accumulation of radioactive transported proteins proximal to the compression zone, was calculated in the following way: the radioactivity in three nerve pieces (two pieces in the proximal part of the compressed area and one piece immediately proximal to the compressed area) was expressed as a fraction of the radioactivity contained in six pieces proximal to the above-mentioned three pieces (Fig. 2 a). Six pieces were chosen since such a procedure reduces the likelihood of the ratio being unduly affected by spurious counts in individual nerve pieces proximal to the site of compression. The ratio in non-injured nerves should be, and was found to be, around 0.5 . Generally, the more pronounced degree of accumulation of radioactive transported proteins was reflected by the higher transport block ratio.

\section{Statistical analysis}

Data were analyzed using the SAS procedure; GLM (General Linear Models) [17]. The Wilcoxon rank sum test was then used to identify individual differences. $p$ values $<0.05$ were considered significant (two-tailed). The values are presented as mean \pm SD.

\section{Comments on methods}

The streptozotocin-diabetic rat is a widely accepted model for inducing diabetic neuropathy. In a previous study, with an insulin-treated group of animals included, we demonstrated that streptozotocin does not have a direct effect on the nerves [6], and therefore we considered it unnecessary to include an insulin-treated group in the present study. There are also some recent indications that excessive, or even accurate, insulin administration may in itself have a detrimental effect on peripheral nerve [18].

\section{Results}

The diabetic rats all had whole blood glucose levels above $13.9 \mathrm{mmol} / 1(250 \mathrm{mg} / 100 \mathrm{ml})$, polyuria, polydipsia and weight loss $(11.5 \% \pm 5.5)$, while control rats had whole blood glucose levels around $5.0 \mathrm{mmol} / 1(90 \mathrm{mg} /$ $100 \mathrm{ml}$ ). Previous and subsequent work in two series, with more precise measurements, have shown fasting blood glucose values of $16.3 \pm 1.5$ and $20.6 \pm 3.5 \mathrm{mmol} / 1$ in streptozotocin-diabetic rats compared with values in control rats of $5.2 \pm 2.2$ and $5.2 \pm 1.2 \mathrm{mmol} / 1$ (McLean, unpublished observations).

Figure 2 a shows a profile of radiolabelled proteins in sham-compressed non-diabetic sciatic nerves. In these sham-compressed nerves there was no accumulation at the site of the chamber as reflected by the low transport block ratio in both the control and the diabetic groups. The ratio was $0.49 \pm 0.11$ in the control group and $0.50 \pm 0.09$ in the diabetic group. These values are similar to the values expected in non-injured nerves, and reflect the constant value of radioactivity in the "plateau" which follows the front of the wave of fast transported radiolabelled proteins into the nerve (Fig. 2a). However, when the pressure in the chamber was increased to $30 \mathrm{~mm} \mathrm{Hg}$ there were various degrees of accumulation at the compressed area. In the control group the transport block ratio was elevated to $0.67 \pm$ 0.16 (Fig. 2b) due to a slight inhibition of fast transport. In the nerves of the diabetic rats, the transport block ratio was increased to $1.01 \pm 0.35$ (Fig. $2 \mathrm{c}$ ). This difference between control and diabetic animals was statistically significant $(p<0.05)$. In experiments in which a ligature was applied around the nerve, the transport block ratio was significantly higher than in nerves compressed at 
$30 \mathrm{~mm} \mathrm{Hg}$, indicating that the block of transport at $30 \mathrm{~mm} \mathrm{Hg}$ was incomplete, even in the diabetic animals. Ligated nerves of diabetic animals had a transport block ratio of $1.45 \pm 0.30$, which was not statistically different from that in control nerves $(1.34 \pm 0.44)$. The results are summarized in Figure 3.

\section{Discussion}

The present study shows that local compression of sciatic nerves at $30 \mathrm{~mm} \mathrm{Hg}$ for $3 \mathrm{~h}$ induces a greater inhibition of fast axonal transport of proteins in rats with streptozotocin-induced diabetes than in controls. The results obtained do not seem to be based on the slower velocity of fast axonal transport known to be present in the diabetic animals [6], which theoretically could lead to a greater accumulation of parts of the front of the wave of radioactive proteins at site of compression. This is clear from the fact that in the ligated nerves only a minor difference $(20 \%)$ in the accumulation of proteins was found between diabetic and control nerves, compared with the greater than three-fold difference in accumulation of proteins produced by compression at $30 \mathrm{~mm} \mathrm{Hg}$.

Several factors may operate to render nerves in diabetic animals more susceptible to compression. In advanced cases of diabetes mellitus the axons may be affected by the microvascular changes that occur in the vasa nervorum of the peripheral nerve [19]. Changes in microvascular structure, compounded by rheological and biochemical disturbances, may cause a reduced endoneurial blood flow and oxygen tension, as was recently described in rats with longterm streptozotocin-induced diabetes mellitus [20]. In another neuropathy in which there is also an increased water content, i.e. galactose neuropathy, a further mechanism may be the elevated endoneurial fluid pressure which causes a decrease in intraneural blood flow [21-23]. It has been assumed that there is an increased susceptibility to compression in such a neuropathy [24]. Local compression of normal peripheral nerve at $30 \mathrm{~mm} \mathrm{Hg}$ induces intraneural circulatory changes as well as increased permeability of endoneurial vessels [25, 26], changes which might be even more pronounced in diabetes. A consequence of such changes might be the marked inhibition of axonal transport induced by compression at $30 \mathrm{~mm}$ $\mathrm{Hg}$ as observed in the present study.

It should be noted that in the present animal model the diabetes was of relatively short duration ( 2 weeks). There are, to our knowledge, no experimental data available indicating any signs of structural microangiopathy at that time. Equally, the blood-nerve barrier remains intact and the endoneurial fluid pressure is nor$\mathrm{mal}$ in nerves in streptozotocin-induced diabetes [22, 27-29]. However, there is evidence of an increased water content as well as expansion of the endoneurial space in this model [30]. The increased water content may lead to a situation in which the nerve fibres are required to take up more of the applied pressure as compared to normal peripheral nerves in which the individual nerve fibres are protected by the structural support of surrounding endoneurial connective tissue. The expansion of the endoneurial space, which could be due to an oedema secondary to increased activity of the sorbitol pathway, may also increase the diffusion distance for oxygen from the endoneurial capillaries to the axons. Furthermore, the delivery of oxygen to the axons may be disturbed by the previously mentioned biochemical and rheological changes even at this short duration of diabetes.

One should also consider the possibility that the diabetes causes changes in retrograde axonal transport which normally delivers information to the nerve cell body concerning the state of the axon and its terminals. Disturbances in retrograde transport, which occur as early as one day after induction of experimental diabetes [31], have been considered to be responsible for the reported decreased velocity of slow transport in diabetes mellitus $[5,32,33]$. Such changes might alter the biochemical integrity of the axon and therefore contribute to the increased susceptibility to compression demonstrated in this study.

Our results support a number of morphological observations, such as more prominent focal demyelination of plantar nerves in diabetic animals than in control animals [2-4]. However, the nerve injuries described in those studies were not induced by compression at a defined pressure magnitude, which is important when comparing the reaction of nerves in diabetic and normal animals. In this respect, the compression chamber used in the present study represents a more valuable device. Clinical and electrophysiological studies on human diabetic patients have also suggested that diabetic nerves are more susceptible to compression trauma than normal nerves $[1,34,35]$. Thus, there are several experimental and clinical studies which indicate, in accordance with the present study, that diseased neurones in diabetes mellitus may be more susceptible to compression trauma [9].

Experimental observations indicate that vibration sense as well as sensory modalities such as touch and pain together with motor nerve conduction velocity are retained better during ischaemia in patients with diabetes than in normal individuals $[36,37]$. One may therefore assume that, in a carpal tunnel syndrome in diabetic patients, the nerve pathology can proceed to a more advanced stage before clinical symptoms become apparent. Our present study also indicates that nerve damage may be even more prominent in diabetic patients due to a greater degree of inhibition of fast axonal transport, since axonally transported materials are considered to be essential for the maintenance of axon terminals as well as certain properties of target organs [38, 39]. An anomalous situation may develop in diabetic patients, i.e. symptoms may take longer to appear de- 
spite the neuropathy being more advanced. It is therefore important that, in diabetic patients presenting with neuropathy, one considers that the symptoms may be a result of local peripheral nerve compression - a condition which can relatively easily be corrected by surgery.

Acknowledgements. This work was supported by grants from the Swedish Medical Research Council (nos. 5188 and 2226), the Göteborg Medical Society, the University of Göteborg, Sweden, and the Wellcome Research Trust, UK. We thank ICI Pharmaceutical (UK) for a gift of streptozotocin.

\section{References}

1. Mulder DW, Lambert EH, Bastrom JA, Sprague RG (1961) The neuropathies associated with diabetes mellitus. Neurology 11 : 275-284

2. Brown MJ, Sumner AJ, Greene DA, Diamond SM, Asbury AK (1980) Distal neuropathy in experimental diabetes mellitus. Ann Neurol 8: 168-178

3. Moore SA, Peterson RG, Felten DL, O'Connor BL (1981) Glycogen accumulation in tibial nerves of experimentally diabetic and aging control rats. J Neurol Sci 52: 289-303

4. Moore SA, Peterson RG, Felten DL, O'Connor BL (1982) Ultrastructural axonal pathology in experimentally diabetic and aging control rats. Brain Res Bull 8: 317-323

5. Sidenius $P(1982)$ The axonopathy of diabetic neuropathy. Diabetes $31: 356-363$

6. Meiri KF, McLean WG (1982) Axonal transport of protein in motor fibres of experimentally diabetic rats - Fast anterograde transport. Brain Res 238: 77-88

7. Tomlinson DR, Mayer JH (1984) Defects of axonal transport in diabetes mellitus - A possible contribution to the aetiology of diabetic neuropathy. J Auton Pharmacol 4: 59-72

8. Dahlin LB, Rydevik B, Lundborg G (1986) Pathophysiology of nerve entrapments and nerve compression injuries. In: Hargens AR (ed) Tissue nutrition and viability. Springer, Berlin Heidelberg New York, pp 135-160

9. Upton ARM, McComas AJ (1973) The double crush in nerve-entrapment syndromes. Lancet $2: 359-362$

10. Lasek RJ (1968) Axoplasmic transport of labeled proteins in rat ventral motoneurons. Exp Neurol 21: 41-51

11. Griffin JW, Drachman DB, Price DL (1976) Fast axonal transport in motor nerve regeneration. J Neurobiol 7:355-370

12. Forman DS, Berenberg RA (1978) Regeneration of motor axons in the rat sciatic nerve studied by labeling with axonally transported radioactive proteins. Brain Res $156: 213-225$

13. Rydevik B, Lundborg G (1977) Permeability of intraneural microvessels and perineurium following acute, graded experimental nerve compression. Scand J Plast Reconstr Surg 11: 179-187

14. Dahlin LB, Rydevik B, McLean WG, Sjöstrand J (1984) Changes in fast axonal transport during experimental nerve compression at low pressures. Exp Neurol 84: 29-36

15. Rydevik B, McLean WG, Sjöstrand J, Lundborg G (1980) Blockage of axonal transport induced by acute, graded compression of the rabbit vagus nerve. J Neurol Neurosurg Psychiatry 43: 690-698

16. Bisby MA (1976) Fast axonal transport and amine levels. Nature 264: $382-383$

17. SAS Institute Inc. (1982) SAS User's Guide: Statistics, 1982 Edition. Cary, NC: SAS Institute Inc, p 139

18. Sharma AK, Duguid IGM, Blanchard DS, Thomas PK (1985) The effect of insulin treatment on myelinated nerve fibre maturation and integrity and on body growth in streptozotocin-diabetic rats. $\mathbf{J}$ Neurol Sci 67: 285-297
19. Powell HC (1983) Pathology of diabetic neuropathy: new observations, new hypotheses. Lab Invest 49:515-518

20. Tuck RR, Schmelzer JD, Low PA (1984) Endoneurial blood flow and oxygen tension in the sciatic nerves of rats with experimental diabetic neuropathy. Brain 107:935-950

21. Myers RR, Costello ML, Powell HC (1979) Increased endoneurial fluid pressure in galactose neuropathy. Muscle Nerve 2: 299-303

22. Myers RR, Powell HC (1981) Endoneurial fluid pressure in peripheral neuropathies. In: Hargens AR (ed) Tissue fluid pressure and composition. Williams \& Wilkins, Baltimore, pp 193-207

23. Myers RR, Powell HC (1984) Galactose neuropathy: Impact of chronic endoneurial edema on nerve blood flow. Ann Neurol 16: 587-594

24. Low PA, Dyck PJ, Schmelzer JD (1982) Chronic elevation of endoneurial fluid pressure is associated with low-grade fiber pathology. Muscle Nerve 5: 162-165

25. Rydevik B, Lundborg G, Bagge U (1981) Effects of graded compression on intraneural blood flow. An in vivo study on rabbit tibial nerve. J Hand Surg 6: 3-12

26. Lundborg G, Myers R, Powell H (1983) Nerve compression injury and increased endoneurial fluid pressure: a "miniature compartment syndrome". J Neurol Neurosurg Psychiatry 46: 1119-1124

27. Jakobsen J, Malmgren L, Olsson Y (1978) Permeability of the blood-nerve barrier in the streptozotocin-diabetic rat. Exp Neurol 60:277-285

28. Sima AAF, Robertson DM (1978) The perineurial and bloodnerve barriers in experimental diabetes. Acta Neuropathol 44: 189-195

29. Powell HC, Costello ML, Myers RR (1981) Endoneurial fluid pressure in experimental models of diabetic neuropathy. $\mathbf{J}$ Neuropathol Exp Neurol 40: 613-624

30. Jakobsen J (1978) Peripheral nerves in early experimental diabetes. Expansion of the endoneurial space as a cause of increased water content. Diabetologia 14: 113-119

31. Sidenius P, Jakobsen J (1981) Retrograde axonal transport. A possible role in the development of neuropathy. Diabetologia 20 : 110-112

32. Jakobsen J, Sidenius P(1980) Decreased axonal transport of structural proteins in streptozotocin diabetic rats. J Clin Invest 66: 292-297

33. McLean WG, Meiri KF (1980) Slow axonal transport of protein in rat sciatic motor nerves during early experimental diabetes. $J$ Physiol 310: 57P

34. Gilliatt RW, Willison RG (1962) Peripheral nerve conduction in diabetic neuropathy. J Neurol Neurosurg Psychiatry 25: 11-18

35. Shahani B, Spalding JMK (1969) Diabetes mellitus presenting with bilateral foot-drop. Lancet 2:930-931

36. Steiness I (1959) Vibratory perception in diabetics during arrested blood flow to the limb. Acta Medica Scand 163: 195-205

37. Gregersen G (1968) A study of the peripheral nerves in diabetic subjects during ischemia. J Neurol Neurosurg Psychiatry 31: 175-181

38. Grafstein B, Forman DS (1980) Intracellular transport in neurons. Physiol Rev 60: 1167-1283

39. Guth L (1968) "Trophic" influences of nerve on muscle. Physiol Rev 48: 645-687

Received: 7 June 1985

and in revised form: 13 January 1986

Dr. Lars B. Dahlin

Laboratory of Experimental Biology

Department of Anatomy

University of Göteborg

Box 33031

S-40033 Göteborg

Sweden 